\title{
Plant Regeneration from the Leaf Explants of Enicostemma littorale Blume through Direct Organogenesis
}

\author{
Nalini, . $^{1}$, Velayutham, ${ }^{2}{ }^{2}$, Karthi, $\mathbf{C}^{3}$ \\ PG and Research Department of Botany, Government Arts College (Autonomous), Karur 639 005, India
}

\begin{abstract}
A rapid and reproducible protocol has been developed for in vitro regeneration of plantlets from leaf explants of Enicostemma littorale Blume (Gentianeceae). Leaf segments isolated from young healthy plants were cultured on MS medium fortified with different concentrations of cytokinins (BAP, KIN) ranging from 5 - $25 \mu$ M or in combination with IAA (2 $\mu M)$. Inclusion of IAA into BAP+KIN supplemented medium triggered a high frequency of regeneration response from leaf explants. Maximum number of shoots (16.3) with highest shoot length $(8.46 \mathrm{~cm})$ were observed on MS medium supplemented with $15 \mu M$ BAP plus 5 MM KIN and 2 $\mu M$ IAA. The isolated shoots were cultured on half strength MS medium containing different concentration of auxins(IAA,IBA and $N A A)$. The best rooting was observed on half strength MS medium augmented with $2 \mu M N A A$. The regenerated plantlets were successfully hardened on foam cups containing soil, farm yard manure and sand (2:1:1) with 75-80\% survival rate.
\end{abstract}

Keywords: Enicostemma littorale , Leaf, Direct organogenesis, Cytokinins, in vitro rooting

Abbreviations: ANOVA: Analysis of Variance; BAP: Benzylaminopurine; DMRT: Duncan Multiple Range Test; IAA: Indole Acetic Acid; IBA: Indole Butyric Acid; KIN: Kinetin (6-Fufuralaminopurine); NAA: Naphthalene Acetic Acid; TDZ: Thidiazuron.

\section{Introduction}

Enicostemma littorale Blume [Syn. Enicostemma axillare (Lam.) A. Raynal], a member of Gentianaceae, is one of the important medicinal plants widely distributed in India. It is an erect or procumbent perennial herb of $5-30 \mathrm{~cm}$ tall, simple or branched at the base. This plant is characterized by the presence of many flowered axillary clusters around the stem.

This plant is known to possess antimicrobial [1]-[4], antiinflammatory [5]-[6], anti-ulcer [7], anthelmintic [8], antinociceptive [9], anti-pyretic and anti-malarial [10], antioxidant [11]-[12], anti-diabetic [13]-[14] and anti-cancer [15] activities.

Plant cell and tissue culture has become a major tool in the study of an increasing number of fundamental and applied programs of plant science. It is a promising area of biotechnology that enables the production of large number of plants with high qualitative and quantitative characters, thus opening new vistas for genetic variability and selection of desired characters [16]. The techniques are being used globally for the ex situ conservation of plants. The endeavour is to adopt the method to multiply the medicinal herbs and monitor their secondary metabolites.

In recent years, there has been an increased interest in in vitro techniques which offer a viable tool for mass multiplication and germplasm conservation of rare endangered aromatic and medicinal plants [17]. The significance of tissue culture technique in rapid and clonal propagation of plants was soon realized and several studies in different plant species were carried out by different workers in the world.
Direct regeneration (absence of an intermediate callus phase) is one of the useful alternative techniques over the conventional methods of vegetative propagation. In direct organogenesis, generally, the plants are directly regenerated from existing meristem or non-meristematic regions like internode, leaf, root, etc.

Direct organogenesis has been reported in various plant species [18]-[20]. Only a few micropropagation studies have been conducted in Enicostemma littorale [21],[22] including the development of epiphyllous buds from the leaves of $E$. hyssopifolium [23].

In the present investigation, a protocol for shoot induction from the leaf explants of E. littorale and further shoot multiplication has been developed. More over, it is also aimed to determine the most appropriate growth regulator and its concentration and combination for the direct shoot organogenesis and rapid multiplication. To achieve the goal, different concentrations and combinations of cytokinins, especially, BAP and KIN were used for shoot regeneration directly from leaves.

\section{Materials and Methods}

\subsection{Source of explants}

The plant material, Enicostemma littorale Blume, was collected from the agricultural field at Sukkaliyur in Karur District of Tamil Nadu, India. The leaf segments were selected for the source of explants in the present study.

\subsection{Preparation of Explants}

The leaf explants were excised and washed with running tap water for 30 minutes. Then they were washed in an agitated 


\section{International Journal of Science and Research (IJSR) \\ ISSN (Online): 2319-7064}

Index Copernicus Value (2013): 6.14 | Impact Factor (2015): 6.391

solution of liquid detergent (Teepol) for 5 minutes and washed with distilled water for 2-3 times. After thorough washing, the materials were taken in to the Laminar Air Flow Chamber where they were disinfected with $70 \%$ alcohol for 30-60 sec followed by $0.1 \%$ mercuric chloride for 3-5 min. Finally, the materials were thoroughly rinsed with sterile distilled water for 4-5 times to remove the traces of mercuric chloride.

\subsection{Preparation of Culture Media}

The basal medium consisted of the mineral salts and organic nutrients of Murashige and Skoog (MS) salts [24], B 5 vitamins [25] with $3 \%$ sucrose and $0.8 \%$ agar. After adding the supplements (various concentrations of different hormones) to the basal media, the $\mathrm{pH}$ of the media was adjusted to 5.8. The molten media were dispensed in culture tubes or conical flasks and were capped with cotton plugs. The culture media were sterilized by autoclaving at $1.06 \mathrm{~kg}$ cm-3 and $121^{\circ} \mathrm{C}$ for $15 \mathrm{~min}$.

\subsection{PGR supplements}

For direct regeneration from the leaf, BAP or KIN alone was tested with different concentrations ranging from $5 \mu \mathrm{M}$ to 25 $\mu \mathrm{M}$. After fixing the optimum concentration, low concentrations of auxin ( $2 \mu \mathrm{M}$ IAA) were supplemented to enhance the multiplication rate. For rooting, three auxins, viz., IAA, IBA and NAA ranging from $2 \mu \mathrm{M}$ to $10 \mu \mathrm{M}$ were used on half strength MS basal medium.

\subsection{Inoculation}

The surface sterilized explants were aseptically transferred to the culture tubes containing the medium different concentrations of plant growth regulators in the Laminar Air Flow Chamber.

\subsection{Culture Conditions}

The cultures were maintained in a culture room at $25 \pm 2^{\circ} \mathrm{C}$ under $16 \mathrm{hr}$ photoperiod with a light intensity of $30-40 \mu \mathrm{M}$ $\mathrm{mm}^{-2} \mathrm{~s}^{-1}$ supplied by cool white fluorescent tubes. The relative humidity $(\mathrm{RH})$ within culture room was maintained at $55 \pm 5 \%$. The media was refreshed at $4 \mathrm{wk}$ intervals.

\subsection{Hardening and Acclimatization}

Four to six week old plantlets with well established roots were removed from the culture tubes and washed the roots to remove the adherent medium. The plantlets were transferred to foam cups ( $8 \mathrm{~cm}$ diameter) containing a mixture of red soil, sand and farm yard manure $(2: 1: 1)$ and maintained inside the culture room at $25 \pm 2{ }^{\circ} \mathrm{C}$ under $16 \mathrm{hr}$ photoperiod and $75-80 \%$ relative humidity. The potted plants were periodically irrigated with water for a period of two weeks and then they were transferred to the field for acclimatization.
2.8. Experimental design, data collection and statistical analysis

All the experiments were preformed using a randomized complete block design and each experiment consisted of ten tubes with one explant in each and five replicates. The parameters recorded were number of shoots per explant, shoot length, number of roots per shoot, root length and survival rate. The analysis of variance (ANOVA) appropriate for the design was carried out to detect the significance of differences among the treatment means were compared using Duncan's Multiple Range Test (DMRT) at a 5\% level of significance [26].

\section{Results and Discussion}

\subsection{Regeneration of shoots from leaves}

The shoots were also regenerated directly from the leaves which were cultured on MS medium with different concentrations of cytokinins (BAP or KIN) ranging from 5$25 \mu \mathrm{M}$. The shoot buds were developed from either cytokinins more or less similarly (Figure - 1; Table-1). However, BAP was found to induce more number of shoots when compared to KIN. At $15 \mu \mathrm{M}$ BAP, mean number of 13.1 shoots per leaf was produced with $98 \%$ shoot induction frequency with $6.14 \mathrm{~cm}$ shoot length. But, average of 11.9 shoots per leaf was induced on medium supplemented with $20 \mu \mathrm{M}$ KIN with $92 \%$ shoot induction frequency with 4.62 $\mathrm{cm}$ shoot length. The experiment was further carried out to increase the number of shoots with the combination of these two cytokinins along with low concentration of auxin, i.e., IAA. Different concentrations of KIN were supplemented with a fixed concentration of $15 \mu \mathrm{M}$ BAP along with $2 \mu \mathrm{M}$ IAA. The leaf explants growing on $15 \mu \mathrm{M}$ BAP plus $5 \mu \mathrm{M}$ KIN and $2 \mu \mathrm{M}$ IAA produced the maximum number 16.3 shoots per leaf with 100 per cent shoot induction frequency. Shoot length was also increased at this combination to 8.46 $\mathrm{cm}$.

Shoot tip and axillary bud cultures are the most efficient techniques for direct regeneration or micropropagation of plantlets through tissue culture technique because of the presence of pre-existing meristem in these regions. However, the shoots were directly regenerated from the nonmeristematic regions like hypocotyl, internode, cotyledon and leaf [18], [27]-[28].

In recent years, direct regeneration of shoots was achieved by several workers by administering various combinations and concentrations of cytokinins and auxins. The medium containing BAP or KIN alone was enough to induce shoots from leaves of some plants [29]. Whereas, BAP or KIN or TDZ in combination with auxins induced shoots in some plants [19]-[20], [30].

Aravind et al. [23] observed the in vitro epiphyllous buds on tender leaves of Enicostemma hyssopifolium on MS medium supplemented with cytokinins (BAP and KIN). They suggested that this phenomenon might be due to cytokinins and occurred only when abaxial surface was in contact with 


\section{International Journal of Science and Research (IJSR) \\ ISSN (Online): 2319-7064 \\ Index Copernicus Value (2013): 6.14 | Impact Factor (2015): 6.391}

the media. However, in the present study, shoots were directly regenerated from either side of the leaves irrespective of the contact surface on MS medium fortified with different concentrations of BAP and KIN alone or in combination with IAA.
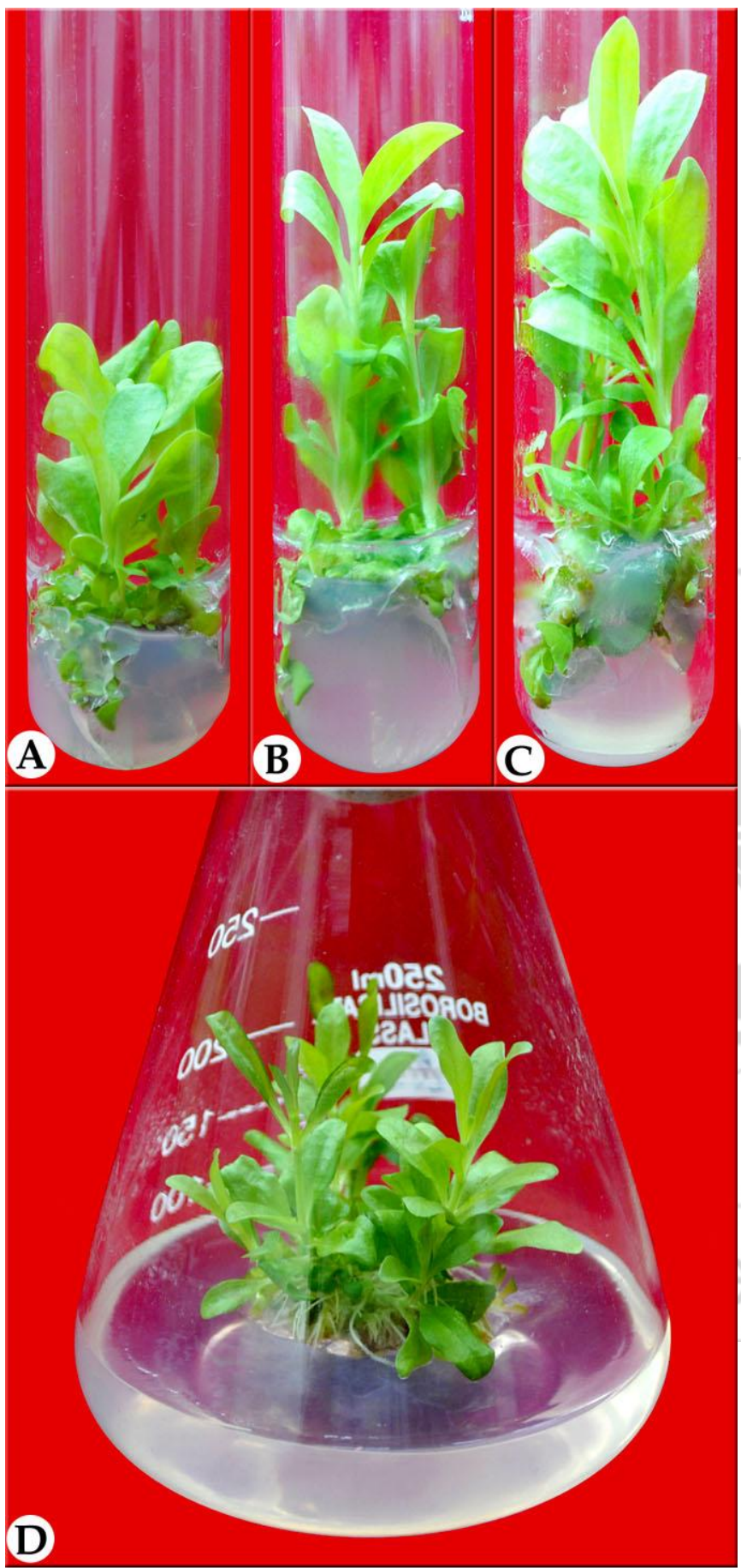

Figure 1: Shoot regeneration from the leaf explants of Enicostemma littorale Blume. A-C. shoot initiation and shoot elongation directly from the leaf; D. Further shoot multiplication.
Table 1: Effect of different concentrations of plant growth regulators on shoot induction and multiplication from the leaf explants of Enicostemma littorale Blume

\begin{tabular}{|c|c|c|c|c|c|}
\hline \multicolumn{2}{|c|}{$\begin{array}{c}\text { Concentrations of } \\
\text { Plant growth } \\
\text { regulators }(\mu \mathrm{M})\end{array}$} & $\begin{array}{c}\text { Shoot } \\
\text { induction } \\
\text { frequency } \\
(\%)\end{array}$ & No. of Shoots & $\begin{array}{c}\text { Shoot length } \\
(\mathrm{cm})\end{array}$ \\
\cline { 1 - 4 } BAP & KIN & IAA & & \\
\hline 5 & --- & --- & 74 & $9.9 \pm 0.95^{\text {ef }}$ & $4.62 \pm 1.01^{\text {hi }}$ \\
\hline 10 & --- & --- & 86 & $10.7 \pm 1.12^{\mathrm{e}}$ & $5.50 \pm 1.02^{\mathrm{fg}}$ \\
\hline 15 & --- & --- & 98 & $13.1 \pm 1.11^{\mathrm{b}}$ & $6.14 \pm 1.07^{\mathrm{e}}$ \\
\hline 20 & --- & --- & 70 & $8.9 \pm 1.08^{\mathrm{g}}$ & $4.65 \pm 1.01^{\mathrm{h}}$ \\
\hline 25 & --- & --- & 64 & $6.9 \pm 1.18^{\mathrm{jk}}$ & $3.49 \pm 1.06^{\mathrm{lm}}$ \\
\hline--- & 5 & --- & 70 & $4.7 \pm 1.00^{\mathrm{m}}$ & $3.77 \pm 1.03^{\mathrm{k}}$ \\
\hline--- & 10 & --- & 76 & $5.9 \pm 1.27^{\mathrm{l}}$ & $3.74 \pm 1.00^{\mathrm{kl}}$ \\
\hline--- & 15 & --- & 80 & $9.9 \pm 1.29^{\mathrm{ef}}$ & $4.29 \pm 1.01^{\mathrm{ij}}$ \\
\hline--- & 20 & --- & 92 & $11.9 \pm 1.70^{\mathrm{d}}$ & $4.62 \pm 1.16^{\mathrm{hi}}$ \\
\hline--- & 25 & --- & 62 & $7.2 \pm 1.25^{\mathrm{ij}}$ & $3.36 \pm 1.01^{\mathrm{mn}}$ \\
\hline 15 & 5 & 2 & 100 & $16.3 \pm 1.57^{\mathrm{a}}$ & $8.46 \pm 1.29^{\mathrm{a}}$ \\
\hline 15 & 10 & 2 & 90 & $13.4 \pm 1.57^{\mathrm{bc}}$ & $8.27 \pm 1.10^{\mathrm{ab}}$ \\
\hline 15 & 15 & 2 & 88 & $11.9 \pm 1.08^{\mathrm{d}}$ & $7.72 \pm 1.20^{\mathrm{c}}$ \\
\hline 15 & 20 & 2 & 76 & $8.6 \pm 1.04^{\mathrm{gh}}$ & $5.83 \pm 1.18^{\mathrm{ef}}$ \\
\hline 15 & 25 & 2 & 70 & $7.4 \pm 1.14^{\mathrm{i}}$ & $6.57 \pm 1.13^{\mathrm{d}}$ \\
\hline
\end{tabular}

Values are Mean of 5 replicates recorded after 30 days of culture. Values in the last two columns are Mean \pm SE of Mean followed by the letters within the column indicating the level of significance at $\mathrm{P}<0.05$ by Duncan's Multiple Range Test (same letter within the column of the respective growth regulator indicates the absence of difference; different letters indicate the significant difference; and combination of letters indicate no significant difference)

\subsection{Rooting of regenerated shoots}

The isolated microshoots of 3-5 $\mathrm{cm}$ length were transferred to rooting medium containing half strength MS salts with different concentrations of three auxins, namely, IAA, IBA and NAA. Rooting was induced in all the three auxins at low concentrations ranging from 2-10 $\mu \mathrm{M}$. Rooting was initiated within a week in all the three auxins and well established in 30 days. However, NAA was found to be better in root induction when compared to IBA and IAA (Figure - 2; Table - 2).

Maximum root induction was observed on medium fortified with $2 \mu \mathrm{M}$ of NAA and IBA with $100 \%$ root induction frequency with mean number of 15.2 and 13.3 roots per shoot respectively. However, more number of roots were initiated when the shoots were grown on NAA compared to that of IBA. Maximum number of 9.5 roots per shoots were initiated from the shoots growing on medium having $6 \mu \mathrm{M}$ IAA with 94\% root induction frequency. From these results, it was observed that NAA favoured root induction from the microshoots of $E$. littorale, followed by IBA and IAA. 


\section{International Journal of Science and Research (IJSR) \\ ISSN (Online): 2319-7064}

Index Copernicus Value (2013): 6.14 | Impact Factor (2015): 6.391

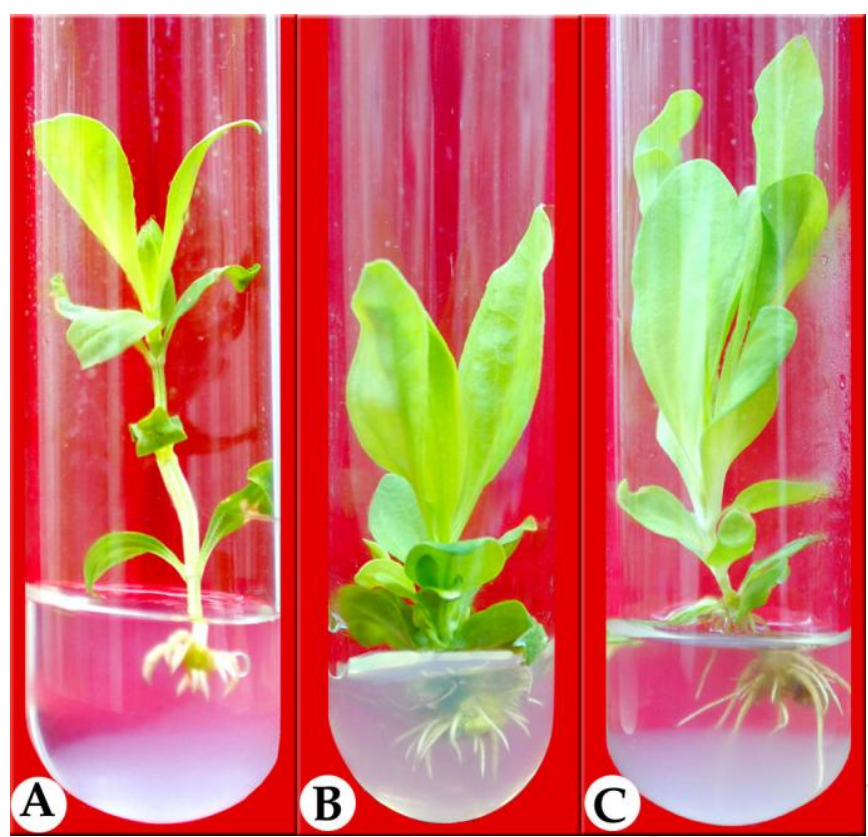

Figure 2: Rooting of isolated shoots of Enicostemma littorale Blume. A. initiation of roots; B. elongation of roots; C. elongation of roots and shoot.

Table 2: Effect of different concentrations of plant growth regulators on rooting of isolated shoots of Enicostemma littorale Blume

\begin{tabular}{|c|c|c|c|c|c|}
\hline \multicolumn{2}{|c|}{$\begin{array}{c}\text { Concentrations of } \\
\text { Plant growth } \\
\text { regulators }(\mu \mathrm{M})\end{array}$} & $\begin{array}{c}\text { Root } \\
\text { induction } \\
\text { frequency } \\
(\%)\end{array}$ & No. of roots & $\begin{array}{c}\text { Root length } \\
(\mathrm{cm})\end{array}$ \\
\cline { 1 - 5 } IAA & IBA & NAA & & \\
\hline 2 & --- & --- & 82 & $6.2 \pm 0.73^{\mathrm{Im}}$ & $3.85 \pm 0.59^{\mathrm{l}}$ \\
\hline 4 & --- & --- & 86 & $8.7 \pm 1.34^{\mathrm{h}}$ & $4.50 \pm 0.81^{\mathrm{h}}$ \\
\hline 6 & --- & --- & 94 & $9.5 \pm 1.80^{\mathrm{fg}}$ & $5.60 \pm 0.64^{\mathrm{c}}$ \\
\hline 8 & --- & --- & 82 & $6.4 \pm 0.78^{\mathrm{l}}$ & $3.53 \pm 0.62^{\mathrm{mn}}$ \\
\hline 10 & --- & --- & 66 & $5.6 \pm 0.89^{\mathrm{mn}}$ & $3.13 \pm 0.73^{\mathrm{o}}$ \\
\hline--- & 2 & --- & 100 & $13.3 \pm 1.36^{\mathrm{cd}}$ & $5.71 \pm 1.24^{\mathrm{b}}$ \\
\hline--- & 4 & --- & 94 & $12.3 \pm 1.42^{\mathrm{e}}$ & $5.08 \pm 1.03^{\mathrm{de}}$ \\
\hline--- & 6 & --- & 86 & $8.6 \pm 1.48^{\mathrm{hi}}$ & $4.87 \pm 0.81^{\mathrm{fg}}$ \\
\hline--- & 8 & --- & 78 & $7.2 \pm 0.78^{\mathrm{jk}}$ & $4.27 \pm 0.73^{\mathrm{ij}}$ \\
\hline--- & 10 & --- & 74 & $6.2 \pm 1.11^{\mathrm{lm}}$ & $3.54 \pm 0.85^{\mathrm{m}}$ \\
\hline--- & --- & 2 & 100 & $15.2 \pm 1.12^{\mathrm{a}}$ & $6.16 \pm 0.89^{\mathrm{a}}$ \\
\hline--- & --- & 4 & 96 & $14.2 \pm 0.60^{\mathrm{b}}$ & $5.22 \pm 1.02^{\mathrm{d}}$ \\
\hline--- & --- & 6 & 94 & $13.8 \pm 0.82^{\mathrm{bc}}$ & $4.89 \pm 1.11^{\mathrm{ef}}$ \\
\hline--- & --- & 8 & 86 & $9.8 \pm 1.13^{\mathrm{f}}$ & $4.47 \pm 0.68^{\mathrm{hi}}$ \\
\hline--- & --- & 10 & 76 & $7.5 \pm 0.53^{\mathrm{j}}$ & $3.91 \pm 0.94^{\mathrm{k}}$ \\
\hline
\end{tabular}

Values are Mean of 5 replicates recorded after 30 days of culture.

Values in the last two columns are Mean \pm SE of Mean followed by the letters within the column indicating the level of significance at $\mathrm{P}<0.05$ by Duncan's Multiple Range Test (same letter within the column of the respective growth regulator indicates the absence of difference; different letters indicate the significant difference; and combination of letters indicate no significant difference

In the present study, of the three auxins tested, NAA was found to induce more number of roots in this plant. Similar results were also observed in Cichorium intybus [18],
Solanum nigrum [31], Hybanthus enneaspermus [32] and Enicostemma littorale [33].

\subsection{Hardening and acclimatization}

The rooted plantlets were initially transferred to the paper cups containing red soil, farm yard manures and sand in the ratio of 2:1:1 (Figure - 3). The survival rate of these plants was $75-80 \%$. Finally they were transferred to the field where they were established well [32]-[34].

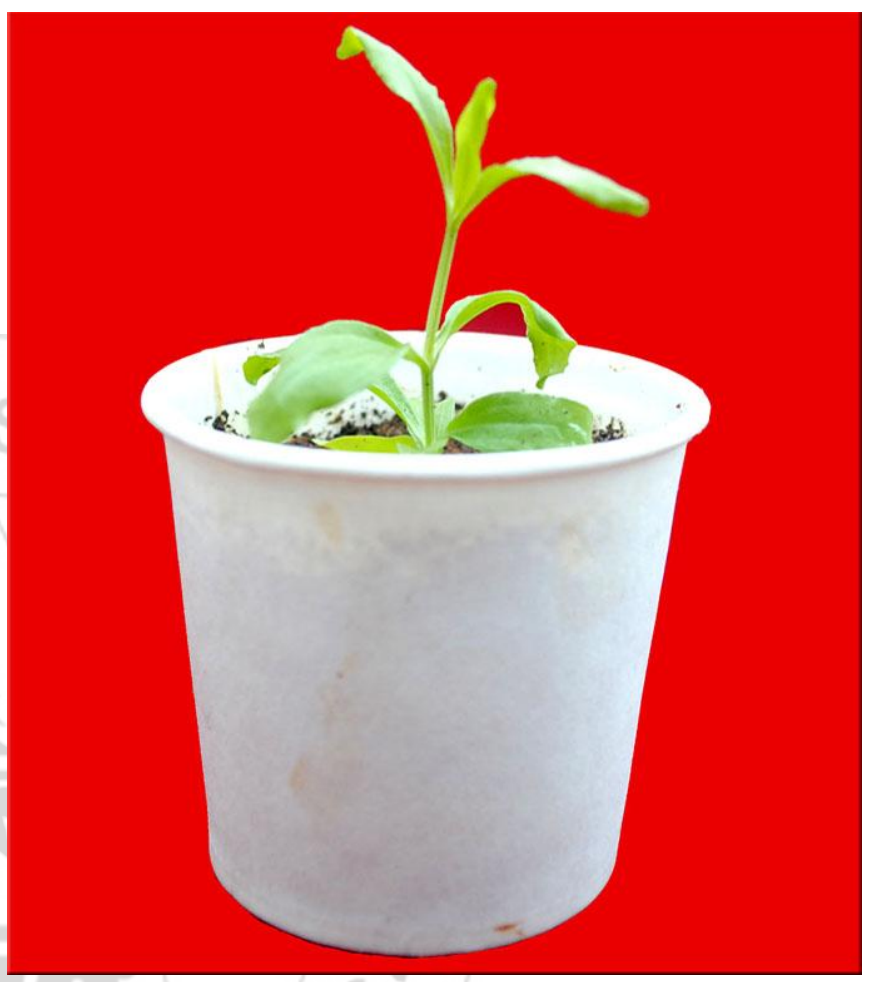

Figure 3: Hardening the rooted plant of Enicostemma littorale Blume.

\section{References}

[1] Praveena, P. and Sudarsanam, D. (2011). In vitro antimicrobial activity studies on Enicostemma littorale (Lam), Raynal Whole plants. Int J Curr Res., 11(3):123-124.

[2] Deore, S.L., Khadabai, S.S., Bhaguire, L. and Ghorpade, D.S. (2008). In vitro antimicrobial and antioxidant studies on Enicostemma littorale (Lam) Raynal. Leaves. Natural Product Radiance, 75:409_ 412.

[3] Tanna, S., Shukla, V.J. and Prajapati, P.K. (2010) Physico-phytochemical evaluation of aqueous extract of Mamajjaka Enicostemma littorale. Int $J$ Pharm Bio Arch., 1(3):309-312.

[4] Patel, R.P. and Trivedi, B.M. (1995). The in-vitro antibacterial activity of the extracts from Enicostemma axillare. Indian Journal of Medical Sciences, 11:887891.

[5] Maroo, J., Vasu, V.T., Aalinkeel, R. and Gupta, S. (2002). Glucose lowering effect of aqueous extract of Enicostemma littorale Blume in diabetes: a possible 


\section{International Journal of Science and Research (IJSR) \\ ISSN (Online): 2319-7064}

Index Copernicus Value (2013): 6.14 | Impact Factor (2015): 6.391

mechanism of action., J. Ethnopharmacol., 81:317320.

[6] Sankaranarayanan, S., Bama, P., Ramachandran, J., Kalaichelvan, P.T., Deccaraman, M., Vijayalakshimi, M., Dhamotharan, R., Dananjeyan, B. and Sathya Bama, S. (2010). Ethnobotanical study of medicinal plants used by traditional users in Villupuram district of Tamil Nadu, India. J Med Plants Res., 4(12):10891101.

[7] Roy, S.P., Niranjan, C.M., Jyothi, T.M., Shankrayya, M.M., Vishawanath, K.M., Prabhu, K., Gouda, V.A. and Setty1, R.S. (2010). Antiulcer and Antiinflammatory Activity of Aerial Parts Enicostemma littorale Blume. J Young Pharm., 2(4):369-373.

[8] Mishra, S. and Shukla, P. (2011). In vitro antihelmintic activity of Enicostemma littorale Blume. Int J Pharma Sci Res, 2(5):1193-1196.

[9] Jaishree, V., Badami S., Kumar, M.P. and Tamizhmani, T. (2009). Antinociceptive activity of Swertaimarin isolated from Enicostemma axillare. Phytomedicine, 16:227-232.

[10] Ookokon, J.E., Nwafor, P.A., Abia, G.O. and Bankhede, H.K. (2012). Antipyretic and antimalarial activities of crude leaf extract and fractions of Enicostemma littorale. Asian Pacific Journal of Tropical Disease, 442-447.

[11] Jaishree, V., Badami, S. and Bhojraj, S. (2008). In-vitro antioxidant activity of Enicostemma axillare. Journal of Health Science, 54:524-528.

[12] Sathishkumar, R., Lakshmi, P.T.V. and Annamalai, A. (2009). Effect of drying treatment on the content of antioxidants in Encostemma littorale Blume. Res J Med Plant, 3(3):93-101.

[13] Murali, B., Upadhyaya, U.M. and Goyal, R.K. (2002). Effect of chronic treatment with Enicostemma littorale in non-insulin-dependent diabetic (NIDDM) rats. $J$. Ethnopharmacol., 81:199-204.

[14] Vishwakarma, S.L., Rakesh, S.D., Rajani, M. and Goyal, R.K. (2010). Evaluation of effect of aqueous extract of Enicostemma littorale Blume in streptozotocin- induced type 1 diabetic rats. Ind $J$ Exp Bio., 48:26-30.

[15] Kavimani, S. and Mani Senthilkumar, K.T. (2000). Effect of methanolic extract of Enicostemma littorale Dalton's ascetic lymphoma. Jour. Ethnopharmacol. 71(1-2):349-352.

[16] Suresh, R. and Rao, M.V. (1994). In vitro clonal multiplication of castor (Ricinus communis L.). J. Swamy Bot. Cl., 11:55-57.

[17] Sudha, G.C. and Seeni, S. (1994). In vitro propagation and field establishment of Adhathoda bedomei C.B.Clarke - a rare medicinal plant. Plant Cell Rep., 13:203-207.

[18] Velayutham, P. and Ranjitha Kumari, B.D. (2003). Direct Regeneration of chicory (Cichorium intybus L.) from leaf explants. Plant Cell Biotechnology and Molecular Biology, 4(3\&4):125-130.

[19] Verma, S.K., Yucesan, B.B., Dahyn, G., Curel, S. and Gurel, E. (2011). Direct shoot regeneration from leaf explants of Digitalis lamarckii, an endemic medicinal species. Turk J Bot., 35:689-695.

[20] Thiruvengadam, M. and Chung, I.M. (2015). Phenolic compound production and biological activities from in vitro regenerated plants of gherkin (Cucumis anguria L.). Electronic Journal of Biotechnology, 18:295-301.

[21] Jeyachandran, R., Anand, S.P. and Thangavel, P. (2005). In vitro micropropagation of Enicostemma axillare through leaf explant. J. Swamy Bot. Club, 22:113-116.

[22] Nagarathnamma, M., Sudarshana, M.S., Niranjan, M.H. and Pandurangamurthy. (2010). Rapid regeneration of Enicostemma littorale Blume from leaf and stem cultures. Journal of Plant Interactions, 5(1):69-73.

[23] Aravind, B., Vijaykumar, B.M. and Seetharam, Y.N. (2014). In vitro epiphyllous buds formation in Enicostemma hyssopifolium (willd.) ver. induction and cellular origin. International Journal of Herbal Medicine, 2 (4): 50-56.

[24] Murashige, T. and Skoog, F. (1962): A revised medium for rapid growth and bio-assays with tobacco tissue cultures. Physiologia Plantarum, 15:473-497.

[25] Gamborg, O.L., Miller, R.A. and Ojima, K. (1968). Nutrient requirements of suspension culture of soybean root cells. Experimental Cell Research., 50:155-158.

[26] Gomez, K.A. and Gomez, K.A. (1976). Statistical procedures for agricultural research with emphasis on Rice. Philippines International Rice Research Institute, Los Bans.

[27] Domelas, M.C. and Viera, M.L.C. (1994). Tissue culture studies on species of Passiflora. Plant Cell Tissue Organ Cult., 36:211-217.

[28] Jasraf, Y.T., Mudgil, Y., Remakanthan, A. and Kannan, V.R. (1999). Direct shoot regeneration from cultured leaves of Passiflora caerulea L. and field performance of regenerated plants. Phytomorphology, 49(3):289293.

[29] Sreedhar, R.V., Venkatachalam, L., Thimmaraju, R., Bhagyalakshmi, N., Narayan, M.S. and Ravishankar, G.A. (2008). Direct organogenesis from leaf explants of Stevia rebaudiana and cultivation in bioreactor. Biologia Plantarum, 52(2):355-360.

[30] Ali, S., Khan, M.S. and Iqbal, J. (2012). In Vitro direct Plant Regeneration From Cultured Young Leaf Segments of Sugarcane (Saccharum Officinarum). J. Anim.Plant Sci. 22(4): 1107-1112.

[31] Jabeen, F.T.Z., Venugopal, R.B., Kiran, G., Kaviraj, C.P. and Rao, S. (2005). Regeneration and in vitro flowering from leaf and nodal explants of Solanum nigrum (L.)- An important medicinal plant. Plant Cell Biotechnology \& Molecular Biology, 6:17-22.

[32] Velayutham, P., Karthi, C., Nalini, P. and Jahirhussain, G. (2012). In vitro Regeneration and Mass Propagation of Hybanthus enneaspermus (L.) F. Muell. from the stem explants through callus culture. Journal of Agricultural Technology, 8(3):1119-1128.

[33] Nalini, P. and Velayutham, P. (2013). In vitro Mass Propagation of Enicostemma littorale Blume from Shoot tip Explants. Journal of Biology, Agriculture and Healthcare, 3(5):72-79. 
[34] Velayutham, P., Ranjithakumari, B.D. and Baskaran, P. (2006). An efficient in vitro plant regeneration system for Cichorium intybus L. an important medicinal plant. Agricultural Technology, 2(2):287-298.

\section{Author Profile}

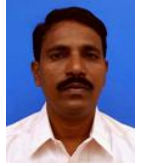

Dr. P. Velayutham did his M.Sc. Botany in 1981 from Presidency College, Madras (Madras University) and M.Sc. Bioinformatics in 2007 from Bharathiar University, Coimbatore. He received his Ph.D. degree in Plant Science from Bharathidasan University, Tiruchirappalli in 2004. He was associated with Dr. M.S. Mani, an eminent Entomologist in a Research Project, Zoological Survey of India, Madras during 1982-85. Then he worked as Post Graduate Teacher in Government Higher Secondary Schools. Currently, he is working as Associate Professor, PG and Research Department of Botany, Government Arts College (Autonomous), Karur, Tamil Nadu, India. His area of specialization is Plant Tissue Culture, established Plant Tissue Culture Laboratory and carrying out UGC Major and Minor Research Projects.

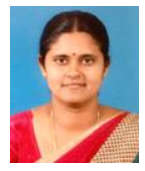

Mrs. P. Nalini, a Part-Time Research Scholar, is working as Post Graduate Teacher in Botany, Government Boys Higher Secondary School, Thondamuthur, Coimbatore District. She did her Under Graduate and Post Graduate Degree Courses from Government Arts College (Autonomous), Karur, affiliated to Bharathidasan University, Tiruchirappalli. She got University First Rank in UG and PG Courses and was awarded UGC merit scholarship for University Rank Holders during her PG course.

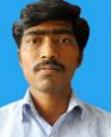

Mr. C. Karthi is a Full-Time Research Scholar, PG and Research Department of Botany, Government Arts College (Autonomous), Karur, Tamil Nadu, India. He did his Under graduation in Government Arts College, Ariyalur and Post graduation in Government Arts College (Autonomous), Karur, affiliated to Bharathidasan University, Tiruchirappalli. 